\title{
Repeat emergency contraception: facing our fears
}

\author{
James D. Shelton* \\ Bureau for Global Health, US Agency for International Development, Washington, DC, USA
}

Received 18 January 2002; received in revised form 5 March 2002; accepted 5 March 2002

Keywords: Emergency contraception; Repeat; Effectiveness; Side effects; Over-the-counter

\section{Introduction}

Emergency contraceptive pills (ECPs) are now established contraception. Providers and clients alike are becoming more familiar with the EC regimen-one dose within $72 \mathrm{~h}$ of unprotected intercourse and a second dose $12 \mathrm{~h}$ later. Two specific ECP preparations are approved by the US Food and Drug Administration, and in the UK and several other European countries ECPs are available without prescription [1]. A number of influential organizations including the American Medical Association and the American College of Gynecology and Obstetrics support over-thecounter (OTC) availability in the US [2].

However, one impediment to OTC availability, and ECP use more generally, has been concern about repeat use or even "abuse" of the method [3,4]. Some providers and program policymakers fear that women might use ECPs indiscriminately, or in the extreme even might use it in lieu of "regular" contraception. However, one study from the UK found that such repeated use was relatively uncommon even when women were given supplies to take home [4] It appears that for the large majority of women dealing with one such emergency is enough.

But is repeat use really so bad? Recent evidence on the newer levonorgestrel (LNG) regimen provides reassurance about effectiveness and side effects. So what do we fear?

\section{Use for a few emergencies}

Two major concerns about repeated use of the old standard estrogen-progestin Yuzpe regimen have been the high rate of objectionable side effects (like nausea, vomiting, and

\footnotetext{
* Tel.: +1-202-712-0869; fax: +1-202-216-3404.

E-mail address: JShelton@usaid.gov (J.D. Shelton).
}

menstrual disruption) and projected high pregnancy rate with repeated use. Yet in a large World Health Organization (WHO) study, LNG alone in two $0.75 \mathrm{mg}$ doses $12 \mathrm{~h}$ apart emerged as a superior ECP regimen, with better efficacy and fewer side effects [5]. Risk of pregnancy when ECPs were initiated within $72 \mathrm{~h}$ was $1.1 \%$ and when initiated within $24 \mathrm{~h}$ the risk was even lower, only $0.4 \%$. Thus, while certainly not ideal, repeating ECPs even a few times still means a fairly low pregnancy risk, especially if with repeat use women have foresight enough to begin within $24 \mathrm{~h}$ of intercourse. Avoiding such emergencies is, of course, a good idea. But based on current evidence, repeating ECPs a few times could still reflect a reasonable risk-benefit for such women.

\section{Primary method for women with infrequent intercourse}

For some women, those with infrequent intercourse, repeatedly taking the newer levonorgestrel regimen on a deliberately premeditated basis may actually be a perfectly reasonable choice as a primary means of contraception. As it turns out, postcoital LNG (in the same $0.75 \mathrm{mg}$ per tablet form, but only a single tablet taken within an hour of intercourse) has a long history of use, not for emergencies but on an ongoing basis. Such use was recently evaluated in another WHO study [6]. Women with average coital frequency of about 4 times per month had a pregnancy risk of $6.8 \%$ per 100 woman-years of use. Such an annual pregnancy risk actually compares favorably to a number of other contraceptive methods, though it is higher than generally seen with hormonal methods. However, pregnancy risk per act of intercourse was only $0.14 \%$. So, for a particular subset of women, those with infrequent intercourse (who might be the very ones most likely to repeat ECP use), the annual pregnancy rate could be quite acceptable. 
Table 1

Calculated cumulative risk of pregnancy for various emergency contraceptive regimens, by number of single-exposure menstrual cycles

\begin{tabular}{lll}
\hline $\begin{array}{l}\text { Number } \\
\text { of cycles }\end{array}$ & $\begin{array}{l}\text { LNG-2 doses begun } \\
\text { Within 24 h }(\%)\end{array}$ & $\begin{array}{l}\text { LNG - 1 dose begun } \\
\text { Within 1 h (\%) }\end{array}$ \\
\hline 1 & 0.4 & 0.14 \\
3 & 1.2 & 0.4 \\
6 & 2.4 & 0.8 \\
13 & 5.1 & 1.8 \\
\hline
\end{tabular}

Is such infrequent intercourse common enough to matter? Yes, according to a nationally representative survey in the US [7]. A full $12 \%$ of married and $8 \%$ of cohabitating women aged 18-59 years reported intercourse frequency of "a few times per year." Further, a review of Demographic and Health Surveys of reproductive-age women in 12 developing countries found that from $4 \%$ to $12 \%$ reported having sex only once in the previous 4 weeks [8]. Some of these women may have fairly regular albeit infrequent sex. Others may have sex very episodically and unpredictably.

Based on the two WHO studies [5,6], one can estimate the annual pregnancy risk with use of LNG as a primary method for women with infrequent intercourse (Table 1). Table 1 assumes that women could initiate use at least within $24 \mathrm{~h}$.

These pregnancy rates compare favorably with many other contraceptive methods, especially barrier methods, withdrawal, and periodic abstinence which have typical use failure rates in the range of $14 \%$ to $40 \%$ [9] and which are logical alternatives for women with infrequent sex. Moreover, when women are using ECPs on a premeditated basis, they ought to be able to start the EC regimen within an hour of intercourse, so the more favorable figures on the far right column might be the more realistic. Indeed, if women start ECPs even before intercourse or use two doses per act of intercourse, the pregnancy risk might be lower still. Also, the calculated risks in the table are average risks across the menstrual cycle, whereas actual risk of pregnancy is substantially higher near midcycle. Premeditated use allows women to supplement ECPs with barrier methods and periodic abstinence around midcycle, thus even further improving effectiveness.

\section{Side effects, safety, and other attributes}

While some side effects such as nausea, vomiting, and dizziness are fewer with the LNG regimen than with Yuzpe, they still occur. On the other hand, many other contraceptive methods have side effects. But in the final analysis, the acceptability of such side effects should be at the discretion of the client. And many women considering repeat ECP use will have already used it and thus have their own experience to weigh.

The long term safety record of daily OCs and injectable progestins supports the safety of repeated LNG ECP use, though not definitively since the regimens are different. Yet sporadic LNG could actually be safer than daily combined OCs. First, there is no estrogen. Second, though $0.75 \mathrm{mg}$ of LNG is five times that of one commonly used OC, the total LNG in the two-dose per episode (1.5 mg) is less than half that in the 21-pill cycle $(3.15 \mathrm{mg})$. More research would help, but current safety information even on the higher-dose Yuzpe regimen is quite reassuring [10,11]. Moreover, WHO has undertaken a systematic review of the medical eligibility for contraceptive methods under various client circumstances. It classifies repeat ECP use under its most liberal eligibility, Category 1 (no restriction) [12].

Advantages of the premeditated LNG strategy include use only when needed, ease of administration, client control, reversibility, and reasonably good effectiveness. Women could alternate or combine use with barrier methods, withdrawal, and periodic abstinence (although use of periodic abstinence could be limited when use of EC results in delay of menses). In addition to the side effects, disadvantages include the need to use soon after intercourse and only infrequently, and no protection from sexually transmitted infection.

Further research on the premeditated approach could address such issues as optimizing the regimen (including evaluating precoital use), safety, and ameliorating side effects.

\section{Conclusions}

Whether premeditated repeated use of ECPs has an important role remains to be seen. But concern about repeat use ought not to restrict availability of ECPs, including OTC availability. It appears few women are likely to repeat use in any case, and those who do will do so sparingly. On the other hand, for those with infrequent sex, use as a primary method for a short time or for longer may actually be a reasonable strategy. Other categories of potential repeat users are of course possible, such as women who might use ECPs multiple times per cycle. But women prone to indiscriminate ECP use might likely be less conscientious with other contraceptive methods including oral contraceptives and barrier methods as well, and it is not clear that, for all of them, ECPs necessarily would carry higher pregnancy risk than use of these methods.

The argument for easy access to ECPs including OTC availability is strong. Providers should certainly make available a full range of contraceptive options, but ultimately women's access to methods should be unimpeded. They should weigh the advantages and disadvantages for themselves.

\section{Acknowledgment}

The views expressed by the author are not necessarily those of USAID. 


\section{References}

[1] Improving access to emergency contraception [editorial]. BMJ 2001; $322: 186$.

[2] Foubister V. OTC emergency contraceptives pushed but not imminent. American Medical News Mar 2001;5:16.

[3] Ziebland S, Graham A, McPherson A. Concerns and cautions about prescribing and deregulating emergency contraception: a qualitative study of GPs using telephone interviews. Fam Pract 1998;15:449-56.

[4] Glasier A, Baird D. The effects of self-administering emergency contraception. N Eng J Med 1998;339:1-4.

[5] Task Force on Postovulatory Methods of Fertility Regulation. Randomized controlled trial of levonorgestrel versus the Yuzpe regimen of combined oral contraceptives for emergency contraception. Lancet 1998;352:428-33.

[6] Task Force on Postovulatory Methods of Fertility Regulation. Effi- cacy and side effects of immediate postcoital levonorgestrel used repeatedly for contraception. Contraception 2000;61:303-8.

[7] Michael RT, Gagnon JH, Laumann EO, Kolata G. Sex in America: a definitive survey. Boston, MA: Little, Brown, and Company, 1994.

[8] Blanc AK, Rutenberg N. Coitus and contraception: the utility of data on sexual intercourse for family planning programs. Stud Fam Plann 1991;22:162-76.

[9] Hatcher RA, Trussell J, Stewart F, et al. Contraceptive technology. $17^{\text {th }}$ ed. New York: Ardent Media, 1998.

[10] Webb A, Taberner D. Clotting factors after emergency contraception. Adv Contracept 1993;9:75-82.

[11] Vasilakis C, Jick SS, Jick H. The risk of venous thromboembolism in users of postcoital contraceptive pills. Contraception 1999;59:79-83.

[12] World Health Organization, Reproductive Health and Research. Improving access to quality care in family planning: medical eligibility criteria for contraceptive use. $2^{\text {nd }}$ ed. Geneva: WHO, 2001. 